\title{
ARTICULANDO VANTAGENS POSICIONAIS: UMA PROPOSTA DE MEDIDA DE CONTROLE PRESIDENCIAL DO PROCESSO LEGISLATIVO
}

Diogo Tavares ${ }^{1}$

\begin{abstract}
RESUMO
Esse trabalho propõe um índice para medir as vantagens posicionais do poder Executivo no processo legislativo da Câmara dos Deputados. Chamaremos de Índice de Controle Presidencial do Processo Legislativo (ICPPL). Para essa medida utilizaremos indicadores posicionais e de distância ideológica entre parlamentares que ocupam funções chaves no processo legislativo e o chefe do Executivo. Foram definidas dezesseis funções legislativas como chaves no processo de definição da agenda. Dentre as funções temos a presidência da Câmara, a presidência e relatoria da comissão mista de orçamento, a presidência da CCJC e de mais quatorze comissões temáticas permanentes da Câmara dos Deputados. Cada posto chave compõe um eixo temático e contribui para com um peso diferente no calculo final do índice. Após a apresentação dos indicadores e dos critérios de pontuação do índice, apresentamos dados exploratórios demonstrando sua aplicação em uma análise observacional de linha do tempo, abrangendo seis legislaturas completas mais o primeiro ano da $56^{\text {a }}$ legislatura compreendendo assim o período de 1995 a 2019. O processo legislativo brasileiro oferece vantagens ao Executivo por meio de prerrogativas institucionais, e de regras internas da Câmara do Deputados, mesmo assim elas não são suficientes para garantir ao Presidente total controle do processo legislativo, para impor sua vontade nesse processo. Assim o ICPPL nos permitira verificar como os Presidentes brasileiros se articulam posicionalmente no processo legislativo, empilhando políticos fiéis ao governo em postos chave. Os primeiros achados exploratórios mostram certa variação no nível de presidencialização nos postos legislativos entre os governos. Foi possível verificar por exemplo, diferenças no domínio presidencial sobre determinadas comissões temáticas entre governos do PSDB e do PT, assim como baixo domínio dos postos chaves no segundo governo Dilma, onde a presidente foi afastada por processo de impeachment. $\mathrm{O}$ índice proposto tem seus limites, mas pode servir como indicador simplificado para medir o poder de influência dos presidentes brasileiros sobre o processo legislativo, assim como de variável independente e de controle para modelos que pretendem explicar o poder de agenda e as taxas de sucesso do Executivo na proposição de políticas.
\end{abstract}

Palavras chave: Presidentes; poder legislativo; poder de agenda.

\section{INTRODUÇÃO}

No mesmo dia em que o Bolsa Família completou doze anos em dezembro de 2015, o relator do Projeto de Lei orçamentária anual (PLOA) de 2016, Deputado Ricardo Barros (PP- PR), anunciou uma proposta de um corte na casa de $\mathrm{R} \$ 10$ bilhões nos recursos da União destinados ao programa.

\footnotetext{
${ }^{1}$ Mestrando no Programa de Pós-graduação em Ciência Política-UFPR. E-mail: di_2712@hotmail.com
} 
A decisão resultaria numa redução de $35 \%$ nas verbas do principal programa social do governo do Partido dos Trabalhadores (PT).

Argumentava o relator que o corte era uma medida necessária para o cumprimento das metas fiscais do governo. O Poder Executivo por sua vez, não era a favor do corte, mas o deputado se dizia a favor como uma alternativa a não reinstaurarão da CPMF, um imposto sobre movimentações financeiras. Acima de tudo a decisão do relator geral do orçamento, impunha limites as preferências orçamentárias do Poder Executivo demonstrando certo poder de reação do legislativo.

Assim como vimos neste caso, o processo de implementação de políticas em regimes democráticos é complexo, e o papel dos legisladores e do poder Executivo varia de acordo com o desenho institucional das democracias, e os mecanismos de estabelecimento de agenda.

A discussão sobre a relação de poderes e a definição da agenda de políticas, é recorrente dos estudos neoinstitucionalistas em ciência política. Uma parte da literatura dedicou-se a compreender o papel dos sistemas partidários para compreender os limites do Executivo (Duverger, 1969); (Sartori, 1976); (Lijphart, 2019), e outro caminho dedicou atenção aos governos e suas estratégias políticas para compreender poder de agenda e os vetos players (Tsebelis, 2009).

Na maioria das democracias os governos são responsáveis pelo estabelecimento da agenda, e a participação do legislativo, depende das prerrogativas que ambos os poderes repartem. Quando os governos são unipartidários o chefe de governo tem mais liberdade para implementar as políticas de sua preferência, pois não reparte o governo com outros grupos partidários em coalizão. No entanto, em governos multipartidários (como no caso do Brasil), o processo de implementação de política depende de um amplo processo de negociação entre as minorias que se unem para formar uma maioria legislativa em coalizão.

Tsebelis (2009) sugere duas variáveis importantes para compreender o poder do governo como definidor da agenda, e os atores com poder de veto em sistemas parlamentares, mas que podem ser facilmente adaptado para o sistema presidencialista. A primeira variável é o que o autor chama de vantagem institucional: consiste na disposição de regras que permitem o governo a apresentar propostas, coloca-las para votar, e ainda vetar propostas de lei que não sejam de sua preferência, as chamadas prerrogativas. A segunda, consiste no que o autor chama de vantagem posicional: o modo como o presidente determina estratégias de posicionamento político, coalizões e alianças com demais partidos considerando as preferências destes, levando em conta principalmente variáveis ideológicas.

Mesmo que o governo controle a agenda com prerrogativas garantidas pela constituição, a reação do parlamento vai depender do desenho institucional que constituem a relação de poderes, e 
as regras do jogo podem prever mecanismos de freios e contrapeso que garantem participação importante do parlamento (Tsebelis, 2009).

Segundo Santos e Almeida (2011) para a teoria funcionalista dos estudos legislativos, é possível identificar o poder de reação do parlamento a partir do papel que ele desempenha na relação estratégias com o Executivo. Essa teoria é capaz de identificar pelo menos três tipos de parlamentos de acordo com o papel que eles exercem nessa relação entre poderes: um parlamento ativo, reativo ou carimbador.

Um parlamento ativo é aquele que domina o processo legislativo, define sua agenda, e é composto por comissões legislativas altamente especializadas, e onde ambição políticas dos legisladores é assumir papel de liderança sobre essas instancias. No outro extremo um parlamento carimbador, é aquele no qual os parlamenteares praticamente cumprem tabela num trabalho legislativo totalmente dominado pelo governo, e onde as comissões parlamentares se resumem a um trabalho técnico proforma. No meio desses extremos está o parlamento reativo, como aquele que delega iniciativa legislativa das proposições mais importantes e a definição da agenda ao Executivo, mas para garantir-se como definidor da agenda, o governo necessita da construção de maiorias legislativas.

Num parlamento reativo, os deputados que lideram a coalizão de governo têm papel essencial em definir estratégias (vantagens posicionais), para proteger as prerrogativas legislativas Executivo (vantagens institucionais), além de trabalhar na difusão de informações sobre as preferências legislativas desse poder do ambiente das comissões para o plenário.

É possível dizer que no caso de parlamentos reativos mesmo que o governo controle a agenda, os deputados podem apresentar restrições importantes as suas escolhas, e que problemas na relação Executivo-Legislativo podem aumentar quando governo e parlamento têm posições políticas diferentes (Santos, Almeida, 2011).

Segundo Amorim Neto (2000) esse processo de restrições de preferências legislativas do Executivo, é mais comum em sistemas de governo com separações de poderes como o presidencialismo do que em sistemas parlamentaristas. Isso se deve ao fato de que no parlamentarismo toda votação legislativa pode servir como voto de confiança ao governo, então não é recomendável que o governo perca numa votação em plenário (Amorim Neto, 2000). Assim, atores com poder de veto não dependem só de instituições e sistemas partidários, mas deriva de ambos (Tsebelis, 2009), vai depender de como governos de coalizão se posicionam estrategicamente nos postos de definição do calendário legislativo (Tsebelis; Há, 2013). 
Com base nessa discussão, esse artigo tem como objetivo propor um índice simplificado para medir o predomínio do presidente sobre o processo legislativo, tendo como foco o posicionamento de parlamentares governistas, oposicionistas ou até mesmo independentes em postos chave do processo de definições de políticas e do calendário legislativo brasileiro.

A proposta, é estabelecer uma medida simplificada capaz de verificar o nível de presidencialização do processo legislativo, buscando mensurar o domínio posicional dos presidentes sobre os postos estratégicos para a definição da agenda no parlamento.

A literatura sobre as relações entre poderes tem classificado o legislativo brasileiro assim como a maioria das democracias latino-americanas, como democracias em que os parlamentos que delegam o poder de agenda ao Executivo (Saiegh, 2009); (Montero e Saez, 2009). São na maioria das vezes, institucionalidades de parlamento reativo, onde a centralização das definições orçamentárias na figura do Executivo, faz com que partidos legislativos gravitem em torno dos interesses do governo (Abranches, 2016).

Porém, mesmo que apresentando características reativas, ocorre no legislativo brasileiro processos específicos como a "cartelização das comissões", por partidos e parlamentares que convergem participação em ministérios com domínio de comissões temáticas na Câmara (Amorim Neto Et. Al. 2003); (Amorin Neto; Santos, 2003), (Inacio; Rezende, 2005). Mas, a maioria dos trabalhos sobre a relação entre Executivo e Legislativo no Brasil, tende a negligenciar o papel que os presidentes e ou as coalizões de governo exercem sobras as comissões, e a necessidade desses atores em estabelecer vantagens posicionais para obter bons resultados no processo legislativo.

Assim, propormos um índice para medir a "presidencialização" do processo legislativo, com base no que já anunciamos aqui como postos estratégicos para a definição calendário legislativo, e da agenda de políticas. Reunimos esse postos em seis blocos principais do controle da agenda: (i) presidência da câmara; (ii) controle do orçamento, presidência da comissão mista e relatoria geral; (iii) presidência da Comissão de Constituição e Justiça ; (iv) presidência das comissões de definição e fiscalização do gasto público; (v) presidência de comissões temáticas permanentes de temas de cunho social; (vi) presidência de comissões temáticas de temas setoriais de desenvolvimento e infraestrutura.

Para verificar o nível de controle do presidente sobre esses postos legislativos, utilizaremos como parâmetro, a proximidade posicional e ideológica dos partidos legislativos que ocupam esses postos, em relação ao Presidente da República e o seu partido, numa escala simplificada oferecida 
pela literatura de esquerda e direita em cinco níveis (Coppedge, 1997); (Amorim Neto, 2000); (Mainwaring, 2003).

Acreditamos que a relação da ocupação desses postos chaves, em governo $x$ oposição mais distância ideológica do ocupante com o governo, tem seus limites pode servir com um indicador simples de controle presidencial sobre o processo legislativo.

Com os dados exploratórios gostaríamos contribuir e chamar a atenção para o fato de que somente as prerrogativas da regra do jogo não garante o predomínio do Executivo sobre a agenda de políticas. Por isso, os presidentes buscam construir maiorias legislativas, empilhando membros fiéis sobre esses postos de controle, como estratégias de garantir com que minorias formas não sejam capazes de agir contra os interesses do governo e suas prerrogativas. Desse modo compreender essas estratégias de domínio posicional é fundamental.

Este paper se divide em 4 partes. A primeira busca fazer uma breve discussão sobre o poder de agenda do Executivo e as possibilidades de reação do legislativo no desenho institucional brasileiro. A segunda, busca discutir as custos e vantagens do presidente em buscar dominar o processo legislativo com base em pressupostos teóricos do neoinstitucionalismo da escolha racional. A terceira parte apresenta nossa proposta de índice de controle presidencial do processo legislativo, e por fim aplicamos o mesmo em 6 legislaturas e no primeiro ano da $56^{a}$ legislatura da Câmara que corresponde ao ano de 2019.

\section{DOMÍNIO DO EXECUTIVO E PODER REATIVO DO PARLAMENTO BRASILEIRO}

$\mathrm{Na}$ maioria das democracias os chefes do Executivo exercem papel predominante do processo legislativo (Saiegh, 2009). No Brasil, há extensas razões institucionais para o domínio Executivo sobre a agenda e os resultados legislativos. A literatura sobre o predomínio do Executivo no Brasil gerou um interessante debate entre cientistas políticos, que se dividiram entre pessimistas e otimistas em relação a institucionalidade brasileira garantir governabilidade e poder de agenda aos presidentes.

Os pessimistas acreditavam que as regras eleitorais e um suposto perfil particularista do parlamentar brasileiro trariam obstáculos significativos para o Executivo operar uma agenda legislativa de políticas nacionais. Os parlamentares até delegariam poder a agenda Executivo, mas em troca, participariam da distribuição de recursos orçamentários, desviando-os para as suas bases eleitorais, o que tornariam essa delegação muito cara, e desincentivaria o processo de discussão de 
políticas (Lamonier; Meneguelo, 1986); (Reis, 1988); (Almeida; 1993); (Kinzo, 1993); (Mainwaring, 1999); (Ames, 2003).

Já os otimistas chamaram a atenção para o efeito centralizador das regras do jogo político brasileiro. O caráter centralizador das estruturas institucionais, concentrariam poderes na figura dos líderes partidários e ao presidente da república, o que seria determinante para que os legisladores se comportem de acordo com a indicação de líderes partidários e de governo (Figueiredo, Limongi, 1999); (Santos, 2003).

Aqui não defenderemos nenhuma das duas teses, mas buscaremos dar ênfase as variáveis endógenas do processo legislativo em nossa análise, assim como os otimistas. Acreditamos que a centralização do processo decisório não se dá de forma automática, mas depende de como o Executivo se posiciona estrategicamente em postos chaves do processo legislativo buscando garantir suas prerrogativas e preferências.

No Brasil o Executivo possui amplos poderes legais para defender seus interesses no legislativo. No entanto algumas instâncias do legislativo sevem de mecanismo de freio e contrapesos frente as preferências do presidente.

Para identificar todos esses mecanismos, é preciso dar atenção ao que Tsebelis (1998), chama de análise das múltiplas arenas. Para o autor, vezes o analista considera determinadas decisões sub ótimas ou irracionais, por que está observando os problemas do jogo principal, e ignora as múltiplas arenas (Tsebelis, 1998).

No entanto, a maioria dos estudos de múltiplas arenas no Brasil, baseados na teoria informacional legislativos norte-americanos relativiza, por exemplo, tem foco sobre o processo de comissões, e se elas são instâncias formais capazes oferecer alternativas as preferências do Executivo (Amorim Neto Et. al, 2003), (Pereira; Mueller, 2004), (Santos; Almeida, 2011).

Para além disso as comissões operam até certo ponto com agentes do Executivo, levando informação qualificada para o plenário, no entanto o Executivo se preocupa em empilhar membros mais fieis em suas composições (Pereira; Mueller, 2004); (Santos; Almeira, 2011).

Porém nosso foco é saber com o Executivo enquanto governo se posiciona politicamente no processo legislativo, para proteger suas vantagens constitucionais, considerando além das comissões, postos como a presidência da Câmara. Há uma série de mecanismos constitucionais e regimentais que nos levam a crer que o Executivo tem poderes absolutos de agenda no Brasil, mas é também é possível levantar prerrogativas de que há poder de reação no Legislativo. Elencamos as principais dessas prerrogativas. 
Dentre os mecanismos mais poderosos a disposição do Presidente da República, está a possibilidade de editar medidas provisórias (MPV). As medidas provisórias são decretos com poder imediato com força de Lei até que o legislativo decida por sua manutenção ou não.

Esse dispositivo não só garante ao presidente amplo poder de legislar, como tem capacidade de dominar a pauta do congresso, trancando a discussão de qualquer outra pauta caso não seja analisado em até 60 dias. Essas propostas quando analisadas pelo legislativo não passam pelas comissões permanentes, são analisadas por comissões especiais mistas, com a participação de membros da Câmara e do Senado indicador por líderes partidários.

Até a implementação da emenda constitucional 32/2001 o presidente brasileiro podia reeditar as MPVs indiscriminadamente. No entanto essa emenda constitucional limitou o número de reedições de MPVs a apenas uma por legislatura, assim como limitou o leque de áreas temáticas pelas quais o Executivo poderia recorrer a essa peça legislativa. Mesmo assim ele não deixou de ser o artifício legislativo mais utilizado pelo Executivo, até mesmo nos governos do PT que tiveram que lhe dar com a nova regra.

Devido ao alcance limitado de temas introduzido as medidas provisórias, os presidentes se viram obrigados a recorrer as demais outras peças legislativas para implementar políticas. Assim, na utilização de projetos de lei ordinárias, outro instrumento importante que dá vantagens às proposições legislativas do Executivo na câmara é o pedido de urgência.

O dispositivo e urgência dispensa, exigências, interstícios ou formalidades regimentais para determinadas proposições. As disposições sobre o requerimento de urgência são regulamentadas pelos Artigos 152, 153, 154, 155, 156 e 157 do Regimento Interno da Câmara dos Deputados.

O Artigo 154 do RICD Regula as possibilidades de apresentação de requerimento de urgência:

Art. 154. O requerimento de urgência somente poderá ser submetido à deliberação do Plenário se for apresentado por: I - dois terços dos membros da Mesa, quando se tratar de matéria da competência desta; II - um terço dos membros da Câmara, ou Líderes que representem esse número; III - dois terços dos membros de Comissão competente para opinar sobre o mérito da proposição (Brasil, 2019).

O pedido de urgência retira um projeto de lei do processo de discussão das comissões e é amplamente utilizado pelos presidentes brasileiros (Pereira; Mueller, 2004). No período analisado pelos autores a maioria dos projetos de lei com pedidos de urgência foram iniciados pelo Executivo (Pereira; Mueller, 2004). 
No entanto, o que se verifica é que a esmagadora maioria dos pedidos de urgências têm anuência da maioria dos líderes partidários, que apesar de terem prerrogativas para derruba-los, poucas vezes ofereceram resistência a esses pedidos. Mesmo aqueles parlamentares e líderes que integram a oposição resistiram pouco, e mostram-se satisfeitos em deliberar projetos em caráter de urgência (Santos; Almeida, 2011).

Outra prerrogativa importante para o Executivo é o controle sobre matérias orçamentárias e da administração pública. Somente o presidente tem prerrogativa para iniciar matérias nessas áreas, e o processo orçamentário do nosso federalismo, é altamente centralizado se comparado a de outros países com as mesmas características (Abranches, 2018). Além de institucionalmente relevante, essa prerrogativa também garante vantagens e poder de negociação do presidente com os parlamentares, ávidos por recursos localistas.

Embora no complexo processo de deliberação sobre o orçamento no Brasil, os congressistas tenham direito de oferecer emendas, a palavra final sobre o pagamento dessas emendas sempre será do Executivo. Normalmente elas são destinadas beneficiar regiões nas quais os parlamentares obtiveram mais votos, o que explica parte da conexão eleitoral no Brasil, e as frenéticas movimentações por recursos orçamentários (Amorim Neto, 2000).

Esse processo garante uma margem de negociação entre o Executivo e aqueles deputados da base de governo mais resistentes, principalmente para a aprovação de matérias que exigem quórum qualificado como as Propostas de Emendas à Constituição (PEC).

Por último, mas não menos importante, outra prerrogativa poderosa nas mãos do Executivo é o poder de veto. Quando um projeto de Lei é aprovado no Congresso ele é enviado ao presidente para a sanção, e este por sua vez pode vetar totalmente, ou oferecer um pacote de vetos parciais a trechos específicos de determinada proposição.

No entanto os vetos não são soberanos, aqui mais uma vez o legislativo tem poder de reagir. Os parlamentares tanto da Câmara quanto do Senado têm direito de deliberar em sessão conjunta (sessão do Congresso), sobre a manutenção ou derrubada dos vetos presidenciais. Assim a votação de MPVs, a análise dos vetos também tranca a pauta do congresso, pois exige-se um calendário específico pra a sua deliberação.

Apesar de um leque de prorrogativas que garantem poderes ao presidente, podemos elencar aqui mecanismos que oferecem exclusivamente poderes ativos e reativos ao parlamento, mais especificamente a Câmara dos Deputados. 
O regimento interno da Câmara centraliza bastante poder nos líderes partidários e no presidente da casa. Alguns incisos do regimento interno da Câmara pontuam as prerrogativas mais importantes do presidente Câmara:

Cabe ao presidente:

Art. 14 e 15. Disposições gerais da mesa:

III - promulgar, juntamente com a Mesa do Senado Federal, emendas à Constituição;

IV - Propor ação de inconstitucionalidade, por iniciativa própria ou a requerimento de Deputado ou Comissão;

XIII - apreciar e encaminhar pedidos escritos de informação a Ministros de Estado, nos termos do art. 50, $2^{\circ}$, da Constituição Federal;

VI - Conferir aos seus membros atribuições ou encargos referentes aos serviços legislativos e administrativos da Casa;

Da Presidência: Arts.16, 17 e 18:

- Organizar, ouvido o Colégio de Líderes, a agenda com a previsão das proposições a serem apreciadas no mês subsequente, para distribuição aos Deputados;

- Designar a Ordem do Dia das sessões, na conformidade da agenda mensal, ressalvadas as alterações permitidas por este Regimento;

- Quanto às proposições: a) proceder à distribuição de matéria às Comissões Permanentes ou Especiais; b) deferir a retirada de proposição da Ordem do Dia; c) despachar requerimentos; d) determinar o seu arquivamento ou desarquivamento, nos termos regimentais;

- Convidar o Relator, ou outro membro da Comissão, para esclarecimento de parecer; convocar as Comissões Permanentes para a eleição dos respectivos Presidentes e VicePresidentes, nos termos do art. 39 e seus parágrafos; f) julgar recurso contra decisão de Presidente de Comissão em questão de ordem;

-Achar a parte que fala que o presidente é o responsável por abertura de processo de impeachment.

- Convocar e reunir, periodicamente, sob sua presidência, os Líderes e os Presidentes das Comissões Permanentes para avaliação dos trabalhos da Casa, exame das matérias em trâmite e adoção das providências julgadas necessárias ao bom andamento das atividades legislativas e administrativas (Brasil, 2019).

Observando o leque de prerrogativas do presidente da Câmara, vale ressaltar que esse ator tem bastante poder, e controle sobre o calendário legislativo e o sistema de comissões. É o presidente, por meio do colégio de líderes, quem define a agenda do plenário de cada mês, e dentro dessa agenda o que será votada em cada sessão. Após decidida a agenda, a ordem de votação das matérias só poderá ser alterada mediante votação de requerimentos de urgência e de preferência, aprovados pela maioria do plenário da Câmara.

As comissões parlamentares também servem como mecanismos de freios e contrapeso para os presidentes. Apesar de parte da literatura afirmar que aparentemente as comissões são desprovidas de poder, elas continuam funcionando ativamente desde a redemocratização, pois na verdade desempenham um papel importante no processo legislativo (Pereira; Mueller, 2004). 
A própria constituição de 1988 deu poder terminativo as comissões temáticas, ou seja, elas podem aprovar projetos sem necessariamente passar por deliberação do plenário. No entanto, mais uma vez aqui tanto o presidente quando os líderes partidários podem deliberar sobre retirar o poder terminativo de determinada proposição. Esses mecanismos são utilizados na maioria das vezes sobre forte acordo.

Os líderes partidários também são responsáveis pela distribuição de cargos nas comissões. Os presidentes de comissões são eleitos anualmente por votação secretas dos membros titulares que a integram. Mas, frequentemente essas eleições resultam de acordos prévios entre os líderes partidários.

Afirmar que as comissões parlamentares no Brasil não desempenham papel significativo no processo legislativo seria um equívoco. Mesmo que o Executivo detenha amplos poderes para defender seus interesses no congresso, e tanto a constituição quanto o regimento interno da Câmara dos Deputados reduzem a possibilidade que esses interesses sejam travados por minorias organizadas, verifica-se que essa vantagem não tem só origens na regra do jogo.

Pereira e Mueller (2004) verificam que que os presidentes se esforçam para empilhar membros leais do governo nas comissões temáticas, afim de aproximar suas preferências da preferência média das comissões.

Os autores mostram que entre 1995 e 1998 a maioria das comissões possuía uma preferência mediana muito favorável as preferências do Executivo (Pereira, Mueller, 2002). Isso sugere que o Executivo não recorreu apenas as suas vantagens institucionais para aprovar políticas de sua preferência, mas buscou organizar vantagens posicionais utilizando as comissões em seu favor (Pereira; Mueller, 2006).

É sobre essa movimentação estratégica que pretendemos nos debruçar. Verificaremos de que forma os presidentes buscaram empilhar não só as comissões, mas os demais postos legislativos da Câmara sobre seu controle com nosso índice. Entes disso, buscaremos argumentar sobre os incentivos racionais e custos da possível omissão do Executivo em organiza maiorias em múltiplas arenas do ambiente legislativo.

\section{ARGUMENTANDO OS CUSTOS DA OMISSÃO DO EXECUTIVO EM ORGANIZAR ESTRATÉGIAS DE VANTAGENS POSICIONAIS NO LEGISLATIVO}


Para pensar nos custos do Executivo em organizar-se no xadrez do processo legislativo, recorreremos a alguns pressupostos do neoinstitucionalismo da escolha racional. Partimos assim da premissa de (Saiegh, 2009), pensando governos numa leitura presidencializada em um ambiente multipartidário: quanto maior os recursos legislativos do partido do governo, menores serão as incertezas quanto a aprovação de matérias legislativas, e menor é o custo da negociação.

A análise do comportamento racional consiste em compreender dois passos importantes: (i) descobrir quais os objetivos que aquele que toma a decisão está perseguindo, (ii) e quais os meios de atingi-los são mais razoáveis (Downs, 2013).

$\mathrm{Na}$ busca pela reeleição, os políticos buscam implementar políticas. O Caminho de implementação de políticas exige tomada de decisão e comportamento estratégico para que a política aprovada seja a política de preferência daquele que a propõem. É preciso assim construir o caminho da vitória, considerando os recursos disponíveis, e as prerrogativas de cada poder como vimos na sessão anterior ${ }^{2}$ (Riker, 1986).

O trabalho de Laver e Shepsle (1990) é fundamental para compreender implementação de políticas em ambientes de constrangimentos institucionais diversos, principalmente nos ambientes cuja a fragmentação partidária exige a formação de coalizões de governo.

Unindo pressupostos dos estudos legislativos norte-americanos, na sua versão informacional, e os estudos Europeus sobre formação de coalizões de governos, os atores afirmam para participar do governo, determinado ator político precisa de informações completas e confiáveis sobre este governo e as políticas que ele pretende aplicar (Laver, Shepsle, 1990).

Para participar de uma coalizão de governo, os partidos legislativos tentarão aprovar políticas mais próximas possível de suas preferências, e farão isso assumindo o corpo técnico e detentor de informações da parte Executiva do governo, ou seja, ministérios e gabinetes (Laver; Shepsle, 1990). Com isso buscarão maximizar suas informações sobre políticas de determinada área, o que lhe oferece vantagens no estabelecimento de agenda com suas preferências, sem esquecer que precisam de aprovação de seus parceiros de coalizão (Laver; Shepsle, 1990).

No entanto, essa lógica se sustenta de maneira mais fácil em governos parlamentaristas de maioria, onde os ministros tem como principal objetivo construir, e implementar políticas de sua área, e dependem de confiança parlamentar (Laver; Shepsle, 1990). Como exemplo, Ministros do Meio

\footnotetext{
${ }^{2}$ Riker chama esse comportamento puramente político de herestética. termo de uma raiz grega que significa "escolher e eleger". Para Riker, o político racional quer vencer no jogo da política. A forma como se ganha é usando retórica (habilidade verbal de persuasão) e a herestética (estruturando o processo para que se possa ganhar) para construir coalizões eficazes.
} 
Ambiente dominarão a agenda legislativa dessa área, e procurarão ter maioria de assentos nas comissões parlamentares que discutem esse tema no legislativo, principalmente se ele tiver um papel ativo na construção e veto de políticas.

Parece fácil pensar esse contexto num sistema de governo parlamentarista. Num ambiente político sem a separação de poderes, o ministro de uma determinada área funciona como administrador, como também principal legislador de determinado tema (Laver; Shepsle, 1990). Mas quando pensamos num sistema de divisão de poderes é um pouco diferente.

Nos sistemas de governo presidencialistas em que se soma a condição de multipartidarismo, nenhum partido no legislativo tem maioria sozinho, e o formador da coalizão nem sempre é o maior partido legislativo ou o partido de centro. Munido de garantias constitucionais, o presidente é eleito para governar num período fixo, que para a sua manutenção independe de uma maioria. Mas na maioria das democracias presidencialistas principalmente na América-latina, os presidentes figuram como o principal legislador, e precisam estabelecer maiorias para aprovar políticas de sua preferência (Montero; Saez, 2009)

Reforçando o que viemos falando aqui, essa possibilidade é determinada por regras, essas que estabelecem os limites da intromissão e da relação entre poderes, que chamamos de prerrogativas, como discutimos, no capítulo anterior.

As prerrogativas dos Presidentes discorrem sobre uma espécie de limites e direitos ao qual esses atores podem lançar mão par participar do processo legislativo, e normalmente versam sobre: (i) Até onde vai o poder legislativo do presidente e sobre o que ele pode legislar?; (ii) quais são as peças legislativas que o presidente pode legislar sobre políticas? (iii) Quais os temas de políticas em que o presidente tem exclusividade para legislar (iv) quais as regras que definem o tramite legislativo das propostas do presidente; (v) Quais as possibilidades de freios e contrapesos dos legisladores a essas propostas em que momento o legislador pode analisar, oferecer alternativas, ou vetar essas propostas políticas.

Aí se dá o processo de definição de vantagens institucionais (Tsebelis, 2009). As vantagens institucionais de um chefe de governo, independente do sistema de governo, elas definirão que "o poder que o Executivo tem", e quais as suas garantias contra a formação de maiorias ou até de minorias (instrumentos contra majoritários) que possam barrar suas preferências no processo legislativo. Diferentes desenhos institucionais podem oferecer mais ou menos vantagens por meio dessas prerrogativas na hora de legislar. 
Em casos onde a constituição não garante prerrogativas suficientes para que chefes de governos aprovem suas políticas sem a necessidade da construção de maiorias qualificadas e robustas, ou seja, não garante vantagens institucionais facilitadoras do trabalho legislativo, os presidentes e primeiros ministros devem recorrer mais fortemente as vantagens posicionais (Tsebelis, 2009).

Assim é necessário se unir com outros agentes do jogo legislativos em alianças temporárias que conhecemos como coalizões. Normalmente como versa a literatura, quando o interesse é aprovar políticas os partidos formam coalizões com parceiros ideológicos mais próximos, ou então a outros agentes dispostos a abrir mão de suas preferências em troca de benefícios que estão ao alcance do poder Executivo - patronagem, pork barrel.

Essas maiorias são constituídas para proteger de modo político as prerrogativas do poder Executivo, buscando facilidades no trabalho legislativo quando as suas prerrogativas são limitaras, ou quando um governo depende da confiança de uma maioria para sobreviver ${ }^{3}$.

Para Laver e Shepsle (1990), num governo parlamentar a política a ser votada em plenário pela maioria, em muitos casos é a política proposta por um ministro da área, raramente é a proposta de um parlamentar isolado, ou da oposição. No presidencialismo brasileiro essa relação é mais difícil de ser identificada. Estudos como o de Inácio e Rezende (2015) versam sobre o controle horizontal da coalizão e sobre a capacidade dos partidos da coalizão em produzir e controlar as políticas dos demais integrantes da coalizão, e até mesmo a oposição pode vir a legislar.

A lógica do sistema de comissões no legislativo brasileiro, nem sempre favorece aos membros da coalizão de governo. Isso porque a figura do presidente das comissões, que funciona como agentes importantes na definição do calendário legislativo, nem sempre são membros de partidos da coalizão de governo. Os presidentes de comissões são decididos por um processo eleitoral que renova o controle da instância anualmente, e em alguns casos é bastante provável que um parlamentar da oposição presida uma comissão permanente.

Mesmo que a constituição brasileira garanta em alguns casos, alternativas para que as proposições do Presidente da República driblem as comissões permanentes da Câmara ${ }^{4}$, as comissões podem funcionar como veto player institucional ao governo. Somado a isso, não há mecanismos

\footnotetext{
${ }^{3} \mathrm{O}$ que não significa que governos minoritários não possam sobreviver também no parlamentarismo em condições onde nem todos os partidos que dão confiança e apoio legislativo ao Primeiro Ministro participam do gabinete ou da parte legislativa do governo. Ver Strom (1990).

${ }^{4}$ Por exemplo as MPs que são votadas em comissões mistas, as PECs que são votadas em comissões especiais, cotando ainda com a prerrogativa de pedido de urgência,
} 
previstos na regra do jogo no Brasil, que permitem ao Executivo vetar projetos que não são de sua preferência já nas comissões permanentes da câmara, sem que elas tenham sido votadas em plenário.

Assim pensando na proposição sobre os recursos legislativos do governo enunciadas no início desse capítulo (Saiegh, 2009), as incertezas e o custo da negociação (Downs, 2015), podemos projetar em uma sequência disponível aos presidentes brasileiros a partir de suas prerrogativas, sobre fases em que esse podem recorrer a vantagens posicionais, que podem ser mais ou menos custosos:

Estratégia 1: O presidente pode ter como aliado os presidentes das comissões, assim como pode ter como aliado presidente de comissões estratégicas importantes para o calendário legislativo como a CCJC, que delibera sobre a constitucionalidade das proposições. Além dos presidentes das comissões temáticas serem membros dos partidos que compõem a coalizão, com menor distância possível com as preferências do presidente.

Estratégia 2: O governo pode organizar uma maioria para vetar e aprovar propostas de sua preferência nas comissões em que tramita determinada proposição. Em uma comissão considerada de oposição, presidida pela oposição, o presidente pode recorrer aos líderes da coalizão de governo para que troquem os membros titulares temporariamente, por membros mais fiéis, até que suas preferências sejam impostas na comissão.

Estratégia 3: O governo pode ter como aliado o presidente da câmara que é quem decide a agenda de votação de projetos no plenário.

Estratégia 4: O líder de governo pode organizar a maioria legislativa para aprovar ou brecar a aprovação de uma política no plenário da câmara, correndo o risco de que parte da coalizão de governo tenha preferência por determinadas políticas que não necessariamente convergem com o governo, o que pode "gerar custos" para o voto disciplinado na coalizão. Esses custos são pagos em forma de patronagem e pork barrel em negociação com os demais líderes partidários ou com deputados individuais no varejo.

Estratégia 5: O presidente tem prerrogativa de vetar (vantagens institucionais), um projeto depois que ele é aprovado na Câmara e no Senado, mesmo assim precisa garantir que uma maioria nas duas casas para manter o veto.

Nessa sequência de estratégias possíveis aos presidentes brasileiros na sua relação com o legislativo no processo de aprovação e veto de políticas, vimos que quanto mais próximo da estratégia 5 , mais custoso pode ser o processo. Por isso, destacamos aqui que as figuras do presidente da Câmara 
e dos presidentes de comissão, são veto players que mesmo com seus limites são importantes no processo legislativo.

Mesmo que os governos tenham dedicado menos atenção do que deveria ao sistema de comissões parlamentares como afirma Amorim Neto (2000), mediante aos argumentos que levantamos aqui, é quase um fato dizer que a o trabalho de organização de uma coalizão legislativa de governo vai além da construção de maiorias para votações em plenário.

Além disso reforçamos a importância de alinhamento com os decisores do orçamento. Mesmo em um ambiente de política de coalizão, não é possível ter mais de uma proposta executável de orçamento. Assim como explicitamos com um exemplo na introdução desse paper, o orçamento da união, que é aprovado pela Câmara, é um instrumento importante para implementar e manter políticas públicas de governo. Ter o controle de preferências dessas políticas é fundamental para os governos.

O alinhamento com a presidência da Câmara também é muito importante num ambiente de separação de poderes, e não é diferente do caso do Brasil. O presidente da Câmara tem ao seu alcance diversas prerrogativas sobre o calendário legislativo do plenário, assim como controle sobre questões decisivas para o Executivo como aceitar ou não pedidos de Impeachment.

Governos que organizam suas vantagens posicionais na arena legislativa, podem vir a garantir maior poder de agenda, maior sucesso legislativo, e estabilidade governativa. No entanto, não temos como sugerir essas afirmações causais sem antes comprovar essa causalidade mediante testes de hipóteses bem elaborados.

Mas para pode realizar testes causais nesses sentidos, precisamos sempre de indicadores, que nos possibilitem uma análise multivariável dessas causas. Por isso esse trabalho propõe a construção de um índice que possibilite mensurar as vantagens posicionais dos presidentes brasileiros no processo legislativo, o índice de controle presidencial do processo legislativo que apresentaremos com mais detalhes na próxima sessão:

\section{CONSTRUINDO UM INDICADOR DE CONTROLE PRESIDENCIAL DO PROCESSO LEGISLATIVO}

Apresento nessa sessão nosso modelo de medida para calcular o controle presidencial sobre os postos-chave do processo legislativo. Com base na discussão realizada até aqui nesse paper sobre custos das translações presidenciais, definimos as posições ideológica dos partidos brasileiros no 
período histórico abrangente, e as posições que entenderemos como postos-chave, para então definir alguns indicadores para o grau de presidencialização dessas funções.

Como medida toma como referência de presidencialização a proximidade posicional e ideológica que ocupante de determinada função do processo legislativo tem em relação ao Presidente da República, buscamos classificar os partidos, e tomamos como premissa a posição ideológica do presidente como sendo similar à de seu partido. Um primeiro passo então foi classificar os partidos brasileiros por clivagem ideológica. Seguindo a sugestão de Coppedge (1997), Maiwring (1999) e Amorim Neto (2000) utilizamos a divisão clássica entre esquerda e direita, divididas em cinco posições: Direita, Centro-direita, Centro, Centro-Esquerda e Esquerda.

Com base em referências disponíveis na literatura sobre o tema na ciência política brasileira, o quadro 1 apresenta a seguinte classificação ideológica dos partidos brasileiros entre 1995-2015:

Quadro 1. Ideologia dos partidos políticos com representação na câmara entre 1995 e 2015:

\begin{tabular}{|c|c|c|c|c|c|}
\hline Períodos & Esquerda & Centro-esquerda & Centro & Centro-direita & Direita \\
\hline $\begin{array}{l}\text { De } 1995 \text { a } \\
2005\end{array}$ & PSTU-PCdoB & PT-PSB-PDT-PV-PPS & PMDB-PSDB & PFL-PTB-PMN-PL & $\begin{array}{l}\text { PPB-PPR-PRONA-PDS- } \\
\text { PRN-PRP-PTC-PTdoB- } \\
\text { PTN-PTR-PST-PSL }\end{array}$ \\
\hline $\begin{array}{l}\text { De } 2005 \text { a } \\
2015\end{array}$ & PCdoB-PSOL & $\begin{array}{l}\text { PT-PSB-PDT-PV-PPS- } \\
\text { REDE }\end{array}$ & PMDB-PSD-PROS & PSDB-PTB-PRB-PMN & $\begin{array}{c}\text { DEM-PP-PR- } \\
\text { PTdoB/Avante-PSL-PSDC- } \\
\text { PRP-PATRI-PTN-PEN }\end{array}$ \\
\hline
\end{tabular}

Pode-se observar na tabela 1. que ocorrem mudanças importantes ao longo do tempo no posicionamento ideológico dos partidos como sugerem diferentes pesquisadores. O PSDB por exemplo, foi classificado como partido de centro nos anos 90 e começo dos anos 2000, e passou para centro-direita no decorrer dos anos de governos do PT.

Buscamos uma classificação intermediária entre a opinião de especialistas, e a classificação em pontuação conforme a metodologia de Power e Zucco $(2009$; 2019) onde o congresso opina sobre ele mesmo.

Considerando então essa classificação ideológica foi possível definir requisitos e condições para determinar o controle presidencial do processo legislativo, com base na distância ideológica dos ocupantes dos postos-chave. Passando par ao próximo passo, outro procedimento realizado foi a definição de pertencimento ou não as coalizões de governo em determinado período, tomando como base de dados sobre coalizões de governo do Cebrap. 
O próximo desafio, foi criar uma variável posicional que incorporasse os diferentes níveis de controle presidencial dos postos legislativos, com base na distância ideológica e na participação ou não na coalizão de governo do ocupante de um posto-chave. Foram definidos então seis requisitos para definir o grau de domínio presidencial de determinada função legislativa:

Quadro 2. Condições para pontuação de controle presidencial do processo legislativo:

1 A função ou cargo é ocupado por um parlamentar do partido do presidente;

2 A função ou cargo é ocupado por um parlamentar do partido do vice-presidente;

3 A função ou cargo é ocupado por um parlamentar de um partido da coalizão de governo ideologicamente próximo ao partido do presidente;

A função ou cargo é ocupado por um parlamentar de um partido da coalizão ideologicamente distante do partido do presidente;

5 A função ou cargo é ocupado por um parlamentar de um partido que não pertence ao governo, mas ideologicamente próximo ao partido do presidente;

6 A função ou cargo ocupado por um parlamentar de um partido que não pertence ao governo ideologicamente distante do partido do presidente;

Fonte: Elaboração própria.

Essas seis condições nos servirão de base e atributos para a pontuação de nosso índice, quanto mais próximo o ocupante das funções que definiremos aqui estiver do primeiro requisito, mais forte a presidencialiszação do cargo, ao contrário, quanto mais próximo do sexto requisito menor o grau de presidencialização.

Assim, foi necessário definir também, o que consideraremos como postos-chaves que utilizaremos para classificar os ocupates. Definimos essas funções e seu peso no indicador, com base no regimento interno da Câmara dos Deputados e com base na literatura da Ciência Política (Amorim Neto, 2000); (Santos, Almeida, 2011); (Pereira e Mueller, 2006).

Essas funções foram divididas em seis grandes blocos, que vão desde a presidência da casa, passando pelo controle do orçamento, pela Comissão de Constituição Justiça e Cidadania (CCJC) e seu controle sobre a constitucionalidade dos projetos, e pelas comissões responsáveis pelo gasto público e fiscalização deste, e finalmente pelas comissões temáticas.

Cada um dos seis eixos temáticos terá um peso sobre índice final. A seguir no quadro 3 elencamos as dezesseis funções legislativas, seu o valor, e o total que cada uma delas irá assumir no valor total de presidencialização, e o peso de cada eixo temático no cálculo final: 
Quadro 3. Cargos chave e valores para composição do índice de controle presidencial do processo legislativo:

\begin{tabular}{|c|c|c|c|c|}
\hline $\mathbf{N}$ & EIXO TEMÁTIVO & CARGO & VALORES & PESO \\
\hline 1 & Mesa/ Plenário & Presidência da Câmara & 1 & 1 \\
\hline \multirow{2}{*}{2} & \multirow{2}{*}{ Orçamento } & Presidência da Comissão Mista de Orçamento & 0,5 & \multirow{2}{*}{1} \\
\hline & & Relatoria Geral do Orçamento & 0,5 & \\
\hline 3 & Constitucionalidade & Presidência da CCJC & 1 & 1 \\
\hline \multirow{2}{*}{4} & \multirow{2}{*}{$\begin{array}{l}\text { Finanças e fiscalização dos gastos } \\
\text { públicos }\end{array}$} & Presidência da Comissão de Tributação e Finanças & 0,5 & \\
\hline & & Presidência da Comissão de Fiscalização Financeira e Controle & 0,5 & \\
\hline \multirow{5}{*}{5} & \multirow{5}{*}{$\begin{array}{l}\text { Comissões permanentes de } \\
\text { temáticas sociais }\end{array}$} & Presidência da Comissão de Educação & 0,2 & \multirow{5}{*}{1} \\
\hline & & Presidência da Comissão de Seguridade Social e Saúde & 0,2 & \\
\hline & & Presidência da Comissão de Direitos Humanos & 0,2 & \\
\hline & & Presidência da Comissão de Relações Exteriores e Defesa Nacional & 0,2 & \\
\hline & & Presidência da Comissão Trabalho, Administração e Serviço Público & 0,2 & \\
\hline \multirow{5}{*}{6} & \multirow{5}{*}{$\begin{array}{c}\text { Comissões permanentes de te } \\
\text { de Infraestrutura e } \\
\text { desenvolvimento }\end{array}$} & Presidência da Comissão de Agricultura e Abastecimento & 0,2 & \multirow{5}{*}{1} \\
\hline & & Presidência da Comissão de Ciência e Tecnologia & 0,2 & \\
\hline & & Presidência da Comissão da Des. da Industria e Comércio e Serviços & 0,2 & \\
\hline & & Presidência da Comissão de Minas e Energia & 0,2 & \\
\hline & & Presidência da Comissão de Viação e Transportes & 0,2 & \\
\hline
\end{tabular}

Fonte: Elaboração própria.

Atualmente a Câmara dos deputados é formada por 25 comissões permanentes, mas aqui utilizo 14. Excluímos da análise as comissões criadas fora do processo da constituinte, presentes no âmbito da Câmara desde 1989. Na maioria dos casos, as comissões que não foram constituídas nesse processo são bastante recentes, então não cobrem um tempo razoável que contribua com nossa análise temporal, e na composição do índice.

O quadro 3 mostra que as comissões ganharam pesos diferentes como indicadores no índice. Essa decisão tem embasamento teórico, numa literatura sobre comissões estudos que argumentam orientam essa decisão (Santos, Almeida, 2011); (Miguel; Feitosa, 2009).

Segundo Miguel e Feitosa (2009) as comissões tem diferentes níveis de importância, e algumas geram mais atenção do que outras pelos definidores da agenda. Devido as prerrogativas exclusivas do Executivo sobre determinados temas, os legisladores com mais influência no legislativo tendem e se concentrar nas comissões em que podem oferecer emendas aos projetos do executivo que são de escala de hard politic (Miguel, Feitosa, 2009).

Outra decisão aqui merece ser justificada. O peso total ao cargo de presidente da Câmara, se orienta nas prerrogativas que esse cargo reúne como demostramos aqui na segunda sessão desse 
paper. Dentre as prerrogativas do presidente da casa, está a possibilidade em discussão conjunta com os líderes partidários e membros específicos constituir novas comissões permanentes. No entanto a mais importante delas é a definição do calendário legislativo para as deliberações em plenário, além da decisão de acatar processos de impeachment apresentadas como notícia crime contra os presidentes.

Outra decisão importante tem relação com a eixo do orçamento. Somente esse bloco envolve um trabalho bicameral. O trabalho da Comissão mista de orçamento é de suma importância e constitui-se com membros da Câmara e do Senado. No entanto, devemos deixar claro que nosso índice de presidencialização aplica-se incialmente par a Câmara-Baixa, que na maioria das decisões legislativas concentra mais prerrogativas que o Senado.

Agora, veremos como pontuar cada ocupante com nosso indicador e realizar cálculo para se obter o índice. Esse índice que propomos para medir a presidencialização da ocupação de postos chave do processo legislativo, chamaremos de Índice de Controle Presidencial dos Postos Legislativos (ICPPL).

$\mathrm{Na}$ tabela 1, indicamos as condições de pontuação para cada ocupante dos cargos, considerando o peso que cada eixo tem para o cálculo final do índice. Sabendo das pontuações em seguida explicaremos como calcular o índice. A ideia é que ele seja um indicador simplificado e de fácil acesso aos interessados nas discussões sobre a capacidade do Executivo de impor sua vontade ao legislativo. 
Tabela 1. Indicadores de pontuação por requisito e ocupante, do Índice de Controle Presidencial dos Postos Legislativos (ICPPL):

\begin{tabular}{|c|c|c|c|c|c|c|c|}
\hline \multirow[b]{2}{*}{ Posição /Situação do ocupante } & \multirow{2}{*}{$\begin{array}{c}\text { Pontuação } \\
\text { do eixo } \\
\text { Referência } \\
\text { de } \\
\text { pontuação } \\
\text { total do } \\
\text { eixo } \\
\end{array}$} & \multicolumn{6}{|c|}{ Pontuação por Requisito } \\
\hline & & $\begin{array}{l}\text { Partido do } \\
\text { presidente }\end{array}$ & $\begin{array}{l}\text { Partido } \\
\text { do vice }\end{array}$ & $\begin{array}{c}\text { Partido da } \\
\text { coalizão } \\
\text { ideologicamente } \\
\text { próximo }\end{array}$ & $\begin{array}{c}\text { Partido da } \\
\text { coalizão } \\
\text { ideologicamente } \\
\text { distante }\end{array}$ & $\begin{array}{c}\text { Partido da } \\
\text { oposição } \\
\text { ideologicamente } \\
\text { próximo }\end{array}$ & $\begin{array}{c}\text { Partido da oposição } \\
\text { ideologicamente } \\
\text { distante }\end{array}$ \\
\hline Presidência da Câmara & 1 & 1 & 0,8 & 0,6 & 0,4 & 0,2 & 0 \\
\hline Presidência da Comissão Mista de orçamento & \multirow{2}{*}{1} & 0,5 & 0,4 & 0,3 & 0,2 & 0,1 & 0 \\
\hline Relatoria geral do orçamento & & 0,5 & 0,4 & 0,3 & 0,2 & 0,1 & 0 \\
\hline Presidência da CCJC & 1 & 1 & 0,8 & 0,6 & 0,4 & 0,2 & 0 \\
\hline Presidência da Comissão de Tributação e Finanças & \multirow{2}{*}{1} & 0,5 & 0,4 & 0,3 & 0,2 & 0,1 & 0 \\
\hline Presidência da Comissão de Fiscalização financeira e controle & & 0,5 & 0,4 & 0,3 & 0,2 & 0,1 & 0 \\
\hline Presidência da Comissão de Educação & \multirow{5}{*}{1} & 0,2 & 0,16 & 0,12 & 0,08 & 0,04 & 0 \\
\hline Presidência da Comissão de Seguridade Social e saúde & & 0,2 & 0,16 & 0,12 & 0,08 & 0,04 & 0 \\
\hline Presidência da Comissão de Direitos Humanos & & 0,2 & 0,16 & 0,12 & 0,08 & 0,04 & 0 \\
\hline Presidência da Comissão de Relações Exteriores e Defesa Nacional & & 0,2 & 0,16 & 0,12 & 0,08 & 0,04 & 0 \\
\hline Presidência da Comissão Trabalho, Administração e Serviço Público & & 0,2 & 0,16 & 0,12 & 0,08 & 0,04 & 0 \\
\hline Presidência da Comissão de Agricultura e abastecimento & \multirow{5}{*}{1} & 0,2 & 0,16 & 0,12 & 0,08 & 0,04 & 0 \\
\hline Presidência da Comissão de Ciência e Tecnologia & & 0,2 & 0,16 & 0,12 & 0,08 & 0,04 & 0 \\
\hline $\begin{array}{l}\text { Presidência da Comissão da Des. da Industria e Comércio e } \\
\text { Serviços }\end{array}$ & & 0,2 & 0,16 & 0,12 & 0,08 & 0,04 & 0 \\
\hline Presidência da Comissão de Minas e Energia & & 0,2 & 0,16 & 0,12 & 0,08 & 0,04 & 0 \\
\hline Presidência da Comissão de Viação e transportes & & 0,2 & 0,16 & 0,12 & 0,08 & 0,04 & 0 \\
\hline
\end{tabular}

Fonte: Elaboração própria. 
Como vimos anteriormente os valores não são meramente discricionários. Outra observação importe é que para pontuar os presidentes da Câmara como alinhados ou não, além do partido foram consideradas as declarações de alinhamento ou não ao governo ou independentes. Como fonte desse posicionamento tomamos discursos na Câmara e ou via meios de comunicação sobre essa relação. Por exemplo, o Deputado Eduardo Cunha (PMDB-RJ), presidente da Câmara no segundo governo Dilma, mesmo que pertencesse ao partido do vice-presidente declarou independência do governo por diversas vezes. Outra consideração é que diferente das demais funções que são funções com eleições anuais, o cargo de presidente da Câmara tem mandato de dois anos.

Feitas as considerações, nos concentramos agora no cálculo propriamente dito. Para o cálculo do índice deveremos considerar a seguinte fórmula:

$$
\mathrm{ICPPL}=\sum(\mathrm{PC}) / \mathrm{Ntb}
$$

Considerando a fórmula, calcula-se o (ICPPL) Índice de pela soma de todos os resultados obtidos com base nos quadros 2 e 3, em cada postos-chave (PC), divididos pelo número total de blocos Ntb que neste caso será igual a 6 , a partir da nossa classificação. O resultado da fórmula varia de 0 a 1, sendo 0 resultado para tipo puro ausência de presidencialização na ocupação dos postos chave no legislativo, e 1 como tipo puro de total presidencialização. Para facilitar a observação também em valores intermediários das pontuações, apresentamos uma escala de valência para interpretação qualitativa dos dados:

Entre 0 e 0,20 Baixíssimo grau de presidencialazação.

Entre 0,20 e 0,40 Baixo grau de presidencialização

Entre 0,40 e 0,60 Médio Grau de presidencialização

Entre 0,60 e 0,80 Alto Grau de presidencialização

Entre 0,80 e 1 - Altíssimo grau de presidencialização

Após a exposição dos indicadores e das técnicas e cálculos para operacionalização do índice, na próxima sessão traremos exemplos de aplicação prática do ICPPL. Para esse exercício utilizamos 
seis legislaturas completas além do primeiro ano da $56^{\mathrm{a}}$ legislatura, período que compreende o recorte temporal entre 1995 a 2019, correspondente também ao período de oito mandatos de cinco presidentes diferentes. Como trata-se de uma pesquisa exploratória, os dados foram expostos em estatística descritiva, trazendo análise de observação temporal, sem pretensões de confirmar teorias causais ou testar hipóteses.

\section{RESULTADOS SOBRE A PRESIDENCIALIZAÇÃO DE POSTOS CHAVE DO LEGISLATIVO BRASILEIRO}

Nesta sessão apresentaremos dados iniciais em um exercício prático da aplicação do Índice de Controle Presidencial do Processo Legislativo (ICPPL) sobre seis legislaturas completas entre 1995 a 2018, e o primeiro ano da $56^{a}$ legislatura 2019. São dados sobre dois governos do PSDB sobre a presidência de Fernando Henrique Cardoso, quatro governos do PT sobre as presidências de Lula e Dilma respectivamente, dos governos de Temer do PMDB e Bolsonaro do PSL.

O primeiro dado explorado traz os resultados da aplicação do índice em série histórica. Podemos observar no gráfico 1 os níveis de controle presidencial do processo legislativo nos últimos 25 anos:

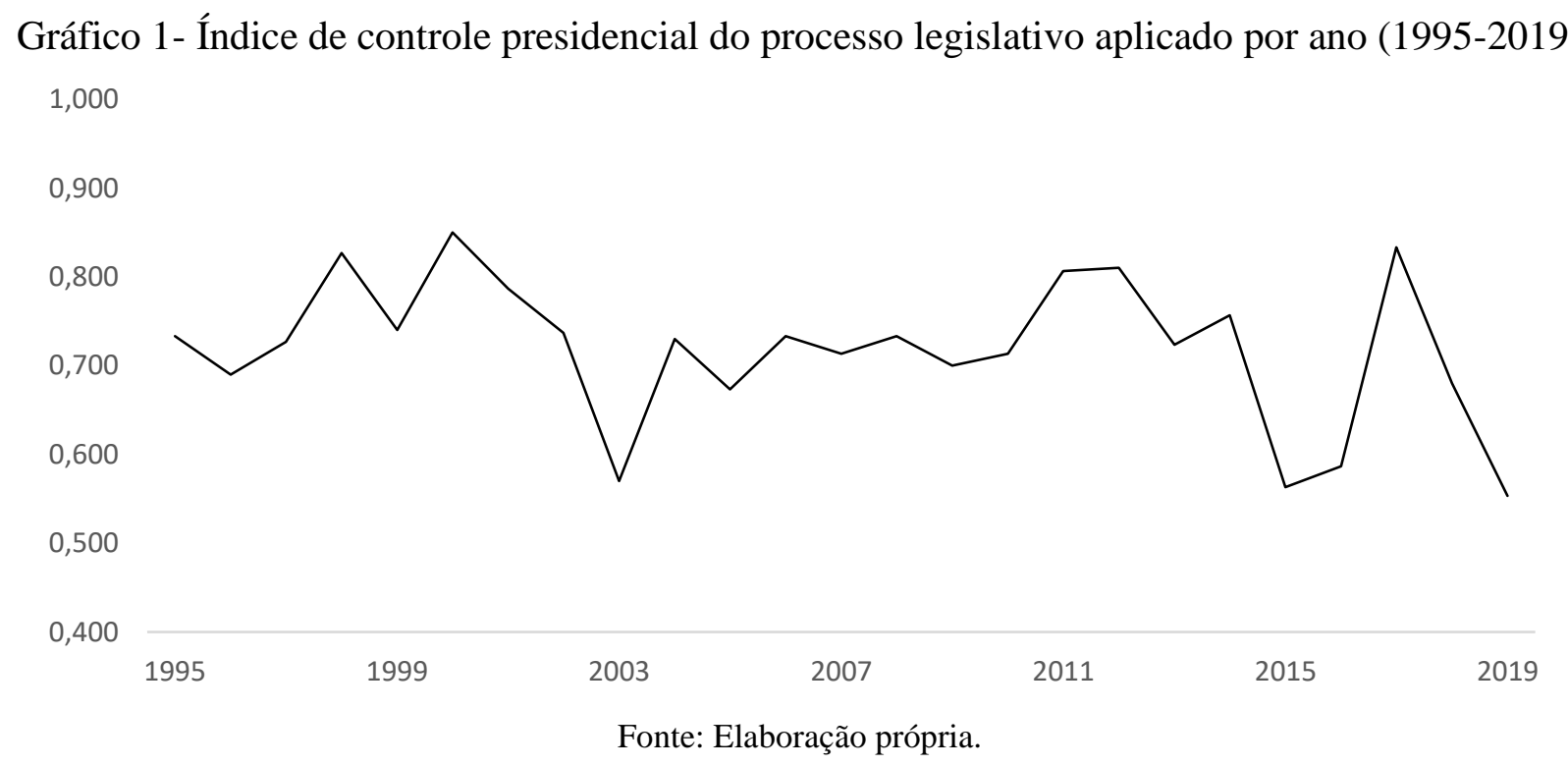

O dado nos mostra certa variação nos resultados do índice na linha do tempo. Podemos verificar altos níveis de presidencialização desses postos chaves no governo FHC, e uma queda brusca 
dos índices em 2003 no primeiro ano do governo Lula. No entanto logo os governos do presidente Lula melhoraram sua marca que se manteve estável. Uma explicação possível foi o tempo para adaptação do novo governo ao processo legislativo, depois de oito anos de alinhamentos dos governos do PSDB que não diferenciou muito dos alinhamentos do governo anterior.

Podemos observar também um aumento nos índices nos primeiros anos do governo Dilma, governo após a transição com Lula. No entanto, há uma forte queda no controle presidencial do processo legislativo no ano que antecede o Impeachment, e em 2016 ano do mesmo.

O índice opera em recuperação nos anos de Temer, e sofre forte queda no primeiro ano de governo Bolsonaro tipo como um governo minoritário, ou seja, uma opção de governo sem formar uma coalizão de maioria.

Num segundo momento podemos observar o índice de forma mais detalhada. Dados mais fragmentados sobre governos, podem nos dar uma noção de predomínio sobre determinados blocos em detrimentos de outros, e comparar os blocos de controle entre presidentes. Podemos observar esses dados na tabela 1:

Tabela 1- Presidencialização dos postos chaves do processo legislativo por presidente e bloco temático:

\begin{tabular}{llcccccc}
\hline Governo & Índice Geral & $\begin{array}{c}\text { Presidência } \\
\text { da Câmara }\end{array}$ & $\begin{array}{c}\text { Controle do } \\
\text { orçamento }\end{array}$ & Constitucionalidade & Financeiro & $\begin{array}{c}\text { Comissões de } \\
\text { temas sociais }\end{array}$ & $\begin{array}{c}\text { Comissões } \\
\text { temáticas de Des. } \\
\text { e Infraestrutura }\end{array}$ \\
\hline FHC I & 0,744 & 0,70 & 0,65 & 0,75 & 0,90 & 0,84 & 0,63 \\
FHC II & 0,778 & 0,80 & 0,78 & 0,90 & 0,88 & 0,54 & 0,83 \\
Lula I & 0,677 & 0,80 & 0,70 & 1,00 & 0,65 & 0,75 & 0,16 \\
Lula II & 0,715 & 0,80 & 0,75 & 0,60 & 1 & 0,71 & 0,43 \\
Dilma I & 0,774 & 0,90 & 0,90 & 1 & 0,88 & 0,68 & 0,29 \\
Dilma II* & 0,575 & 0,40 & 0,70 & 0,60 & 0,80 & 0,66 & 0,24 \\
Temer* & 0,757 & 0,80 & 0,80 & 1 & 0,80 & 0,54 & 0,60 \\
Bolsonaro** & 0,553 & $0,40 * * *$ & 0,60 & 1 & 0,80 & 0,28 & 0,24 \\
\hline
\end{tabular}

*Consideramos governo Dilma II, os de 2015 ano da posse da presidenta e o ano de 2016, ano do impeachment da mesma. Já para classificar como governo Temer foram considerados os anos de 2017 e 2018 . Os presidentes de comissões e relatores do orçamento, são normalmente eleitos e designados no início de cada ano legislativo, por isso a distinção dessa forma.

**Para o governo Bolsonaro foi considerado apenas o primeiro ano para fins de comparação. Fonte: Elaboração própria.

A tabela 1, nos dá uma dimensão comparativa entre governos. Podemos observar que os governos do PT tiveram dificuldades para ter controle sobre o bloco de comissões temáticas de infraestrutura. As comissões como a de agricultura, minas e energia, e transportes, são exemplos de 
comissões cartelizadas (Amorim Neto Et. al, 2003), dominadas por determinados partidos desde o processo de constituinte, onde os partidos de esquerda tem mais dificuldade de penetração.

Outro dado interessante, é o baixo índice de proximidade com a presidência e com a comissão de Constituição e Justiça dos governos Dilma, postos chave para no desenrolar do processo de Impeachment.

Vale destacar a diferença na distância ideológica das coalizões do governo do PSDB e do PT. A fragmentação partidária e a composição do legislativo brasileiro ofereceram condições diferentes para montagem das coalizões, e as coalizões dos governos do PT se caracterizavam como coalizões superdimensionadas e ampla distância ideológica.

Se considerarmos a afirmação de (Saiegh, 2009) de que o tamanho do partido do chefe de governo (presidente) no Legislativo é um importante para determinar a capacidade do Executivo de impor sua vontade ao legislativo, podemos dizer que esse processo pode ser prejudicado pela fragmentação partidária no parlamento.

Um importante indicador pra medir fragmentação partidária é o Número Efetivo de Partidos Parlamentares (NEPP) de Lakso e Taajapera (1979). É uma medida que transforma o número real de partidos em um número possíveis de partidos com poder de veto no parlamento.

Quando aplicamos a medida do NEPP no parlamento brasileiro e cruzamos com o número de partidos que assumiram os dezesseis postos chave que compõem o nosso índice, vemos que com o tempo, há um número maior de partidos no controle desses postos, como podemos observar no gráfico 2.

Gráfico 2- N de partidos em postos chave no legislativo e Número Efetivo de Partidos Parlamentares no Brasil (1994-2019)

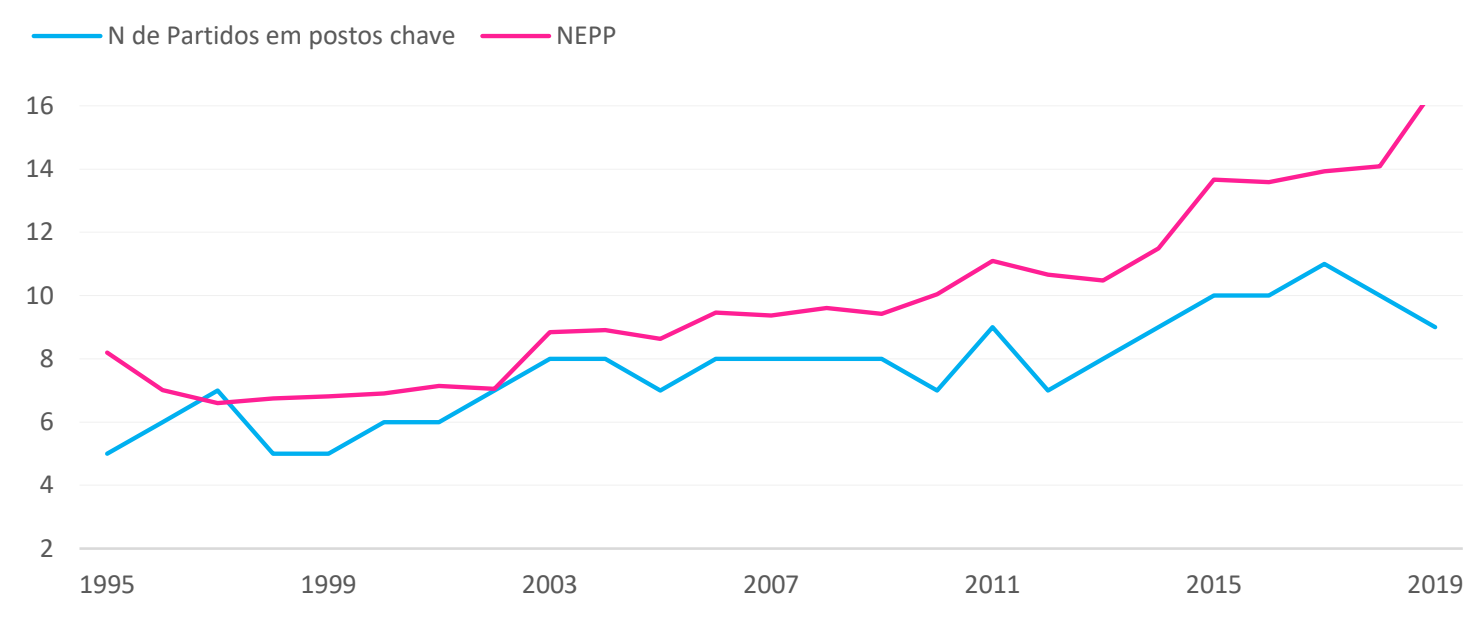

Fonte: Elaboração própria. 
Podemos observar a fragmentação partidária como um possível complicador ao nível de presidencialização do processo legislativo. Vemos que o número de partidos sobre o controle dos postos chave elencados para o índice, aumenta à medida que sobe também o número de partidos parlamentares efetivo.

Nos governos FHC apenas cinco partidos dominavam as dezesseis funções. Nesse período a maioria dos postos concentravam-se entre o PSDB, PFL e PMDB, partidos do governo, e um espaço reduzido para partidos menores no governo como o PPB, e para a oposição com o PT. Com partidos já estabelecidos foram crescendo e assumindo funções chaves com o novo governo, e ainda partidos novos surgiram nesse processo participando da divisão de cargos.

\section{CONSIDERAÇÕES FINAIS}

Apresentado e testado, afirmo que o índice de controle presidencial do processo legislativo tem seus méritos, mas também limitações. Dentre os méritos é a possibilidade de uma medida simples, facilmente aplicável sem a necessidade de processos operacionais complexos. Esse índice, tem valor acadêmico como variável independente ou de controle em modelos que pretendam explicar o poder de agenda e as taxas de sucesso presidencial no legislativo. Mas também tem um potencial de aplicação prática a relatórios de consultoria política sobre as movimentações do governo no processo legislativo.

Dentre as limitações está o fato de que essa é uma medida posicional, e não busca aferir decisões dos ocupantes dos postos chave do processo legislativo. É uma medida alternativa que demonstra certa movimentação do corpo Executivo e da coalizão de governo no processo legislativo, mas que não mensura se esse domínio reflete em decisões pró ou contra o governo.

Mas uma observação empírica importante, é que com a aplicação do índice podemos observar que podemos sugerir que os presidentes buscam vantagens posicionais no processo legislativo para garantir suas prerrogativas. Em diversos momentos pudemos verificar presença do partido do presidente na presidência da Câmara, mesmo que este não fosse o maior partido do legislativo. $\mathrm{O}$ domínio das comissões permanentes, tanto as mais importantes como aquelas que discutem méritos temáticos dos projetos, mesmo que suas prerrogativas do Executivo permitissem dribla-las, o presidente buscou emplacar os seus fiéis, e nos momentos que não o fez pode ser coincidentes com períodos de crise na relação entre poderes. 
Em alguns momentos pudemos observar resultados máximos do índice sobre o domínio da constitucionalidade dos projetos, no controle da Comissão de Constituição Justiça e Cidadania (CCJC), e do controle das comissões financeiras de fiscalização, diretamente ligada a decisões sobre o gasto público.

Contudo esse paper é um projeto inicial sobre esse indicador, no qual acreditamos que ao lançarmos para avaliação dos pares podemos receber críticas e sugestões importantes para melhorar o potencial de aplicação e utilização do índice.

\section{REFERÊNCIAS}

ABRANCHES. Sérgio. Presidencialismo de coalizão: Raízes e evolução do modelo político brasileiro. Companhia das letras, Rio de Janeiro, 2018.

ALMEIDA, M. H. T. 'Em defesa da mudança'. Novos Estudos CEBRAP 35: 15-20, 1993.

AMES, Barry. Os entraves da democracia no Brasil. Rio de Janeiro: Fundação Getúlio Vargas, 2003.

AMORIM NETO, Octavio. Gabinetes presidenciais, ciclos eleitorais e disciplina legislativa no Brasil. Dados [online]. 2000, vol.43, n.3, pp.479-519.

AMORIM NETO, Octavio; COX, Gary; MCUBBINS, Mathew. Agenda Power in Brasil's Câmara dos Deputados, 1989-98. Word Politics, vol. 55, pp. 550-78.

AMORIM NETO, Octavio; SANTOS, Fabiano. O segredo ineficiente revisto: o que propõem e o que aprovam os deputados brasileiros. Dados. Vol. 46. № 4. 2003, pp. 661-698.

BRASIL. Regimento interno da Câmara dos Deputados. 17ª edição, Brasília, 2019.

COPPEDGE, Michael (1997), "A Classification of Latin American Political Parties". Working Paper $n^{\circ} 244$, Kellog Institute.

DOWNS, Antony. Uma Teoria econômica da Democracia. Edusp, São Paulo, 2013.

FIGUEIREDO, Argelina; LIMONGI, Fernando. Executivo e legislativo na nova ordem constitucional. Editora FGV: Rio de Janeiro, 1999.

INACIO, Magna; REZENDE, Daniela. Partidos legislativos e governo de coalizão: controle horizontal das políticas públicas. Opin. Publica [online]. 2015, vol.21, n.2, pp.296-335.

Kinzo, M. D. G. Radiografia do quadro partidário brasileiro. Fundacão Konrad Adenauer: São Paulo, 1993.

Laakso, M.; R. Taagepera. Effective Number of Parties: A Measure with Application to West Europe. Comparative Political Studies 12:3-27, 1979. 
LAMOUNIER, Bolivar; MENEGUELLO, Raquel. (1986) Partidos políticos e consolidação democrática. Editora Brasiliense: São Paulo.

LAVER, Michael; SHEPSLE, Kenneth (1990). "Coalitions and Cabinet Government". The American Political Science Review, v. 84, n. 3.

LIJPHART, Arend. Modelos de democracia: Desempenho e padrões de governo em 36 países. Civilização Brasileira. $4^{\text {a }}$ Edição, Rio de Janeiro, 2019.

Mainwaring, Scott. Democracia presidencialista multipartidária: o caso do Brasil. Lua Nova 28/29: 21-74, 199 .

MAINWARING, Scott. Rethinking Party Systems in the Third Wave of Democratization: The Case of Brazil. Stanford, Stanford University Press, 1999.

MIGUEL, Luis Felipe; FEITOSA, Fernanda. O gênero do discurso parlamentar: mulheres e homens na tribuna da Câmara dos Deputados. Dados - Revista de Ciências Sociais, v. 52, n. 1, 2009.

MONTERO, Mercedes G.; Sáez, Manuel A. Os determinantes do sucesso legislativo presidencial na América Latina. In: Legislativo brasileiro em perspectiva comparada. Org: INÁCIO, Magna; RENNÓ, Lucio, Editora UFMG, 2009.

PEREIRA, C.; MUELLER, B. Uma teoria da preponderância do poder executivo. O sistema de comissões no legislativo brasileiro. Revista Brasileira de Ciências Sociais, v. 15, n. 43, p. 45-67, 2000.

PEREIRA, Carlos; MUELLER, Bernardo. Comportamento Estratégico em Presidencialismo de Coalizão: As Relações entre Executivo e Legislativo na Elaboração do Orçamento Brasileiro. DADOS - Revista de Ciências Sociais, Rio de Janeiro, Vol. 45, nº 2, 2002, pp. 265 a 301.

REIS, Fabio. W. 'Partidos, ideologia e consolidação democrática', in F. W. Reis and G. O'Donnell (eds.) A democracia no Brasil: dilemas e perspectivas. Editora Vértice: São Paulo, 296-326.

RIKER; Willian. The Art of Political Manipulation. New Haven: Yale UP, 1986.

SAIEGH, Sebastian M. Avaliação das taxas de sucesso legislativo dos chefes do executivo. In: Legislativo brasileiro em perspectiva comparada. Org: INÁCIO, Magna; RENNÓ, Lucio, Editora UFMG, 2009.

SANTOS, Fabiano. O Poder Legislativo no presidencialismo de coalizão. Editora UFMG: Belo Horizonte, 2003.

SANTOS, Fabiano; ALMEIDA, Acir. Fundamentos informacionais do presidencialismo de coalizão. Editora Appris. Curitiba, 2011.

SARTORI, Giovanni. Parties and party sistens. New York. Cambrige University Press, 1976.

STROM, Kaare. Minority government and majority rule. Cambridge, Cambridge University Press, 1990. 
TSEBELIS, George. Jogos Ocultos. EDUSP: São Paulo, 1998.

TSEBELIS, George. Atores com poder de veto: como funcionam as instituições políticas. Rio de Janeiro. Editora FGV, 2009.

TSEBELIS, G.; HA, E. Coalition theory: A veto players' approach. European Political Science Review, v. 6, n. 3, p. 331-357, 2013. 